\title{
Sistem Informasi Monitoring Perkembangan Skripsi dengan Reminder System untuk Mahasiswa
}

\author{
Siti Monalisa ${ }^{1}$, Boni Kurniadi ${ }^{2}$ \\ ${ }^{1,2,3}$ Program Studi Sistem Informasi Universitas Islam Negeri Sultan Syarif Kasim \\ (Jl. HR. Soebrantas KM.15, Pekanbaru, Riau) \\ (e-mail: ${ }^{1}$ siti.monalisa@uin-suska.ac.id, ${ }^{2}$ kurniadiboni@gmail.ac.id)
}

\begin{abstract}
Abstrak
Skripsi adalah mata kuliah yang harus ditempuh oleh seorang mahasiswa menjelang akhir studinya. Mata kuliah ini berbentuk proyek mandiri yang dilakukan oleh mahasiswa di bawah bimbingan dosen pembimbing. Pada mahasiswa fakultas psikologi untuk melakukan skripsi memiliki 3 proses yang harus dilalui sehingga tugas akhir dinyatakan telah selesai diantaranya proses seminar proposal, proses seminar hasil dan proses munaqasah. Setiap proses memiliki batas waktu dengan ketentuan apabila melewati batas maka dianggap gagal dan harus mengulang proses sebelumnya. Sehingga menyebabkan mahasiswa kurang mengetahui informasi batas waktu penyelesaian dari setiap proses skripsi. Selain itu pihak fakultas mengalami kesulitan mengetahui sejauh mana perkembangan penelitian skripsi yang telah dilakukan oleh mahasiswa. Oleh karena itu solusi yang bisa lakukan dari masalah tersebut adalah dengan membangun sistem informasi monitoring sehingga pihak Fakultas bisa melakukan pengontrolan skripsi mahasiswa. Bagi mahasiswa sistem informasi monitoring ini akan dilengkapi dengan fitur peringatan untuk setiap tahapan yang dilakukan oleh mahasiswa pada matakuliah skripsi. Salah satu fiturnya adalah reminder system dengan tools yang bisa digunakan adalah email. Dengan adanya sistem informasi monitoring dengan fitur reminder system maka diharapkan mahasiswa termotivasi dalam menyelesaikan skripsinya dengan cepat.
\end{abstract}

Kata kunci: Monitoring, Reminder System , Skripsi, Sistem Informasi

\section{Abstract}

Final Project is a course that must be taken by a student towards the end of his studies. This course is in the form of an independent project undertaken by the Student under the guidance of a supervising lecturer. In Psychology Faculty students to do thesis has 3 processes that must be passed so that the final project is declared has been completed such as proposal seminar process, seminar process and munaqasah process. Each process has a time limit with the provisions when crossing the limit it is considered a failure and must repeat the previous process, because the students lack of knowing the time limit of completion of each thesis process. In addition the faculty has difficulty knowing the extent to which the development of research thesis that has been done. Therefore the solution that can be done from this problem is to build a monitoring information system so that the Faculty can control students. For students the monitoring information system will be equipped with a warning feature for each stage carried out by students in the thesis course. One feature is a reminder system with tools that can be used is email. With the information monitoring system with a reminder system feature, it is expected that students will be motivated in completing their thesis quickly.

Keywords: Information System, Monitoring, Reminder System, Final Project

\section{Pendahuluan}

Pada umumnya Perguruan Tinggi menerapkan matakuliah menjelang akhir studinya berupa karya ilmiah yang disebut skripsi Mata kuliah ini berbentuk proyek mandiri yang dilakukan oleh mahasiswa dibawah bimbingan dosen pembimbing. Karya ilmiah yang dimaksud berupa laporan penelitian yang ditulis sesuai dengan pedoman skripsi dan format 
yang telah ditentukan oleh masing-masing perguruan tinggi. Semua Perguruan tinggi memiliki matakuliah ini pada kurikulumnya dan mahasiswa wajib mengambil matakuliah tersebut seperti pada perguruan tinggi UIN Suska Riau pada Fakultas Psikologi.

Fakultas Psikologi pada perguruan tinggi Universitas Islam Negeri Sultan Syarif Kasim memiliki 1264 mahasiswa pada tahun akademik 2016-2017 yang didapat dari data wawancara dengan bagian akademik. Total mahasiswa yang melaksanakan skripsi berjumlah 255 mahasiswa yang dibimbing oleh 28 dosen pembimbing dengan 3 bagian jurusan yaitu Psikologi Industri dan Organisasi (PIOS), Psikologi Pendidikan dan Perkembangan (PPP) dan Psikologis Klinis dan Agama (PKA). Setiap fakultas mengharapkan semua mahasiswa tepat waktu dalam menyelesaikan skripsinya. Namun yang terjadi dilapangan banyak mahasiswa yang lambat dalam menyelesaikan matakuliah ini. Banyak faktor yang menyebabkan hal ini seperti kebijakan fakultas dalam penyelesaian skripsi, kendala-kendala dalam menuntaskan skripsi, dan usaha mahasiswa dalam merampungkan skripsinya [1]. Berdasarkan penelitian [2] bahwa salah satu hal yang dapat mempercepat penyelesaian skripsi adalah kemampuan menulis. Namun kemampuan menulis yang bagus jika tidak diberikan batasan maka akan membuat mahasiswa juga lengah dalam menyelesaikannya. Sehingga perlu adanya pengontrolan atau monitoring oleh pihak fakultas pada setiap tahapan yang dilalui oleh mahasiswa.

Fakultas Psikologi memiliki 3 (tiga) proses yang harus dilalui oleh mahasiswa hingga skripsi dinyatakan selesai. Proses tersebut adalah proses seminar proposal, proses seminar hasil dan proses munaqasah (Sidang Akhir). Agar ketiga proses tersebut bisa dilewati dengan baik dan cepat maka perlu adanya batasan waktu yang di buat sehingga mahasiswa termotivasi dalam menyelesaikan skripsinya. Batasan waktu tersebut memiliki ketentuan yaitu apabila melewati batas waktu pada masing-masing proses maka dianggap gagal dan harus mengulang proses sebelumnya. Pengontrolon pada setiap tahapan telah dilakukan oleh Fakultas Psikologi namun mengalami kesulitan dalam memonitoring dan memberikan informasi kepada mahasiswa sesuai dengan proses yang sedang dilaluinya. Informasi mengenai batasan waktu setiap wahasiswa tersebut hanya ditempelkan dimading. Hal ini dianggap kurang efektif dalam memberikan informasi dan dianggap tidak efektif dalam melakukan pengontrolan. Salah satu cara yang bisa dilakukan untuk mengatasi hal tersebut adalah adanya sistem informasi monitoring berbasis web [3] yang mempermudah dalam pengontrolan [4] yang dilakukan oleh pihak-pihak Fakultas seperti Dosen, Bagian Akademik, Dekan dan lainnya. Bagi mahasiswa sistem informasi monitoring ini akan dilengkapi dengan fitur peringatan untuk setiap tahapan yang dilakukan oleh mahasiswa pada matakuliah skripsi. Salah satu fiturnya adalah reminder system dengan tools yang bisa digunakan seperti SMS [5-7], email dan lain sebagainya. Dengan adanya sistem reminder tersebut maka akan mempengaruhi intervensi perubahan perilaku [8]. Penelitian ini menggunakan email sebagai tools untuk pengiriman informasi reminder system yang dikirim seminggu sebelum datangnya deadline tersebut ke masing-masing mahasiswa. Dengan adanya sistem informasi monitoring dengan fitur reminder system maka diharapkan mahasiswa termotivasi dalam menyelesaikan skripsinya dengan cepat.

\section{Metode Penelitian}

Penelitian ini menggunakan data primer dan sekunder pada Fakultas Psikologi UIN Suska Riau. Data primer diperoleh dari data observasi dan wawancara pada pihak Fakultas Psikologi yaitu dekan, bagian akademik, dosen dan mahasiswa . Data Sekunder diperoleh berupa datadata mengenai profil instansi, serta studi pustaka mengenai teori-teori yang mendukung penelitian yaitu berupa buku-buku dan jurnal-jurnal penelitian terlebih dahulu. Berdasarkan observasi didapat data berupa prosedur yang terjadi dalam melakukan monitoring perkembangan skripsi. Prosedur inilah yang akan diteliti dan dikembangkan menjadi Sistem Informasi.

Penelitian ini menggunakan metode waterfall [9] dalam pengembangan sistem informasi dan OOAD (Object Oriented Analysis Design) sebagai metode analisa dan perancangan sistem informasi [10]. Data yang telah dikumpulkan maka dilakukan analisa. Tahapan ini merupakan tahapan pertama dari fase waterfall dari penelitian ini. Pada tahap ini akan dianalisis proses 
bisnis mengenai monitoring perkembangan Skripsi dan selanjutnya diusulkan perbaikan dari proses bisnis. Sebagai output dari analisa akan dibuat rancangan interface sistem informasi monitoring perkembangan penelitian skripsi. Selanjutnya akan dilakukan pengkodingan dengan menggunakan bahasa pemrograman PHP [11] dan MySQL sebagai tool DBMS nya sehingga menghasilkan output Sistem informasi Perkembangan Monitoring Skripsi.

\section{Hasil dan Pembahasan}

\subsection{Analisa Sistem yang sedang Berjalan}

Sistem Informasi monitoring perkembangan skripsi pada Fakultas Psikologi UIN Suska Riau belum terintegrasi, artinya pengolahan data-data yang berkaitan dengan akademik di Fakultas Psikologi telah menggunakan Aplikasi Microsoft Acces yang hanya bisa diakses oleh pihak akademik saja. Namun, proses memberikan informasi tentang perkembangan penelitian skripsi kepada ketua bagian dan dosen pembimbing masih melalui print out. Selain itu, belum adanya sistem otomatisasi pemberitahuan kepada mahasiswa pada masing-masing proses yang telah dan sedang dilaluinya. Alur pada sistem yang berjalan saat ini dapat dilihat pada Gambar 1 .

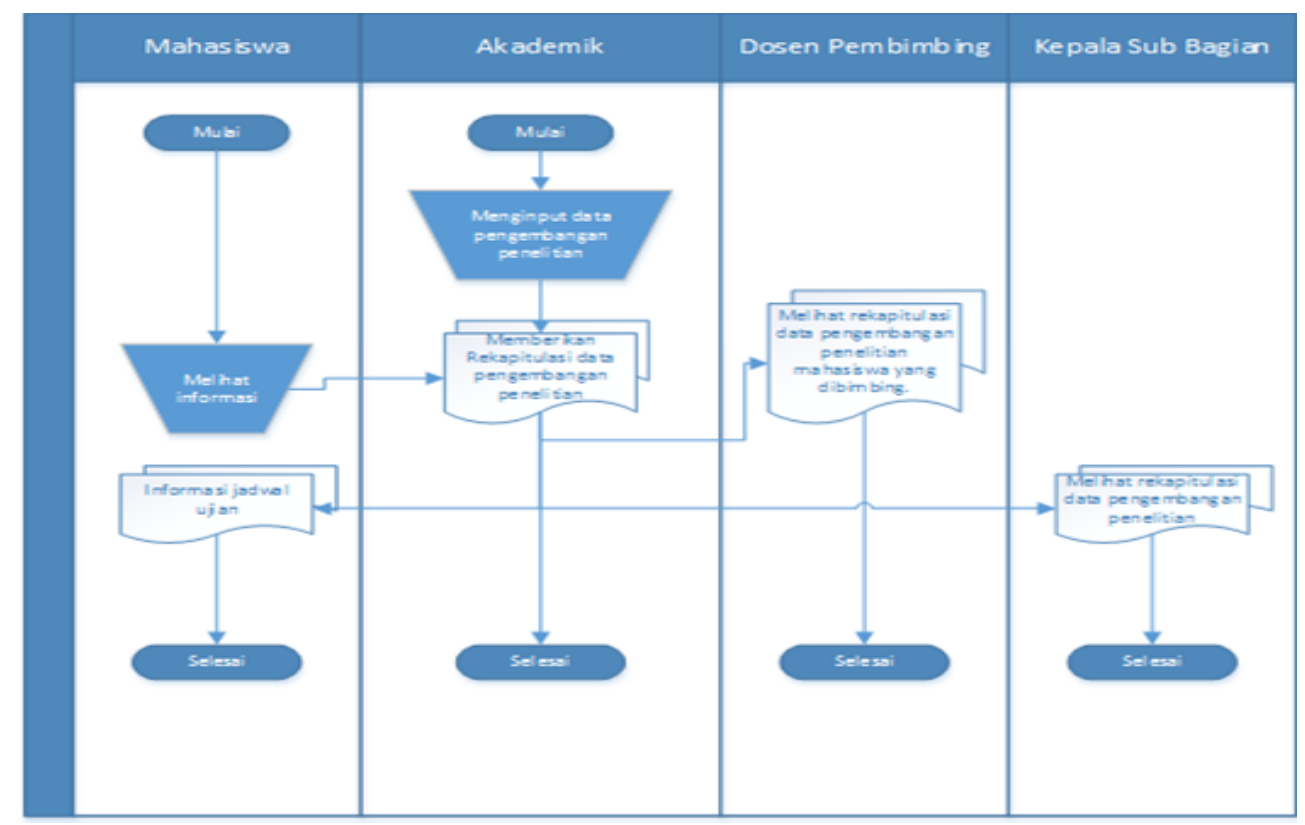

Gambar1: Sistem yang sedang berjalan saat ini

\subsection{Sistem yang diusulkan}

Sistem yang diusulkan dianalisa dan dirancang dengan menggunakan metode analisa dan perancangan Object Oriented Analysis and Design (OOAD) dengan tools Unified Modeling Language (UML) terdiri dari use case diagram, activity diagram, sequence diagram dan class diagram serta perancangan database. Pada Gambar 2 menunjukkan usecase diagram usulan pada sistem reminder system pada sistem informasi monitoring perkembangan skripsi.

Berdasarkan Gambar 2 berupa sistem usulan diatas selanjutnya dikembangkan menjadi perancangan sistem dengan metode Object Oriented Analysis and Design (OOAD) dengan tools Unified Modeling Language (UML). Diagram, yaitu use case diagram, activity diagram, sequence diagram dan class diagram serta perancangan database, perancangan struktur menu sistem dan perancangan user interface. Rancangan tersebut menjadi dasar melakukan pengkodingan pembuatan Sistem Informasi Monitoring Skripsi. Tampilan sistem yang dibuat ditunjukkan pada Gambar-Gambar dibawah ini. 


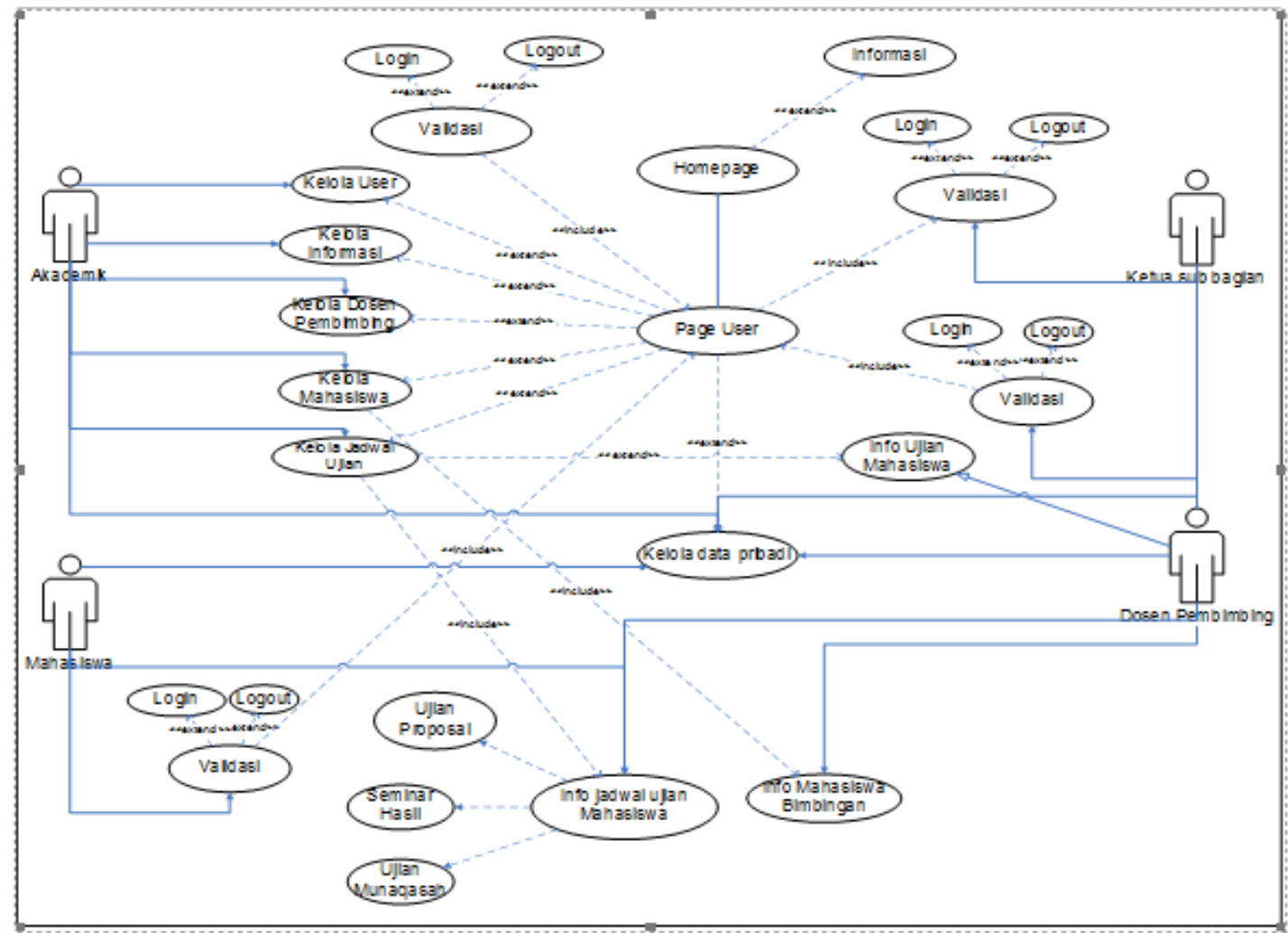

Gambar 2 Use Case Diagram Sistem Usulan

Tampilan pertama yaitu Tampilan Login. Pada tampilan halaman login ini terdapat menu-menu untuk login dengan mengisi username dan password. Tampilan dari halaman tersebut dapat dilihat pada Gambar 3

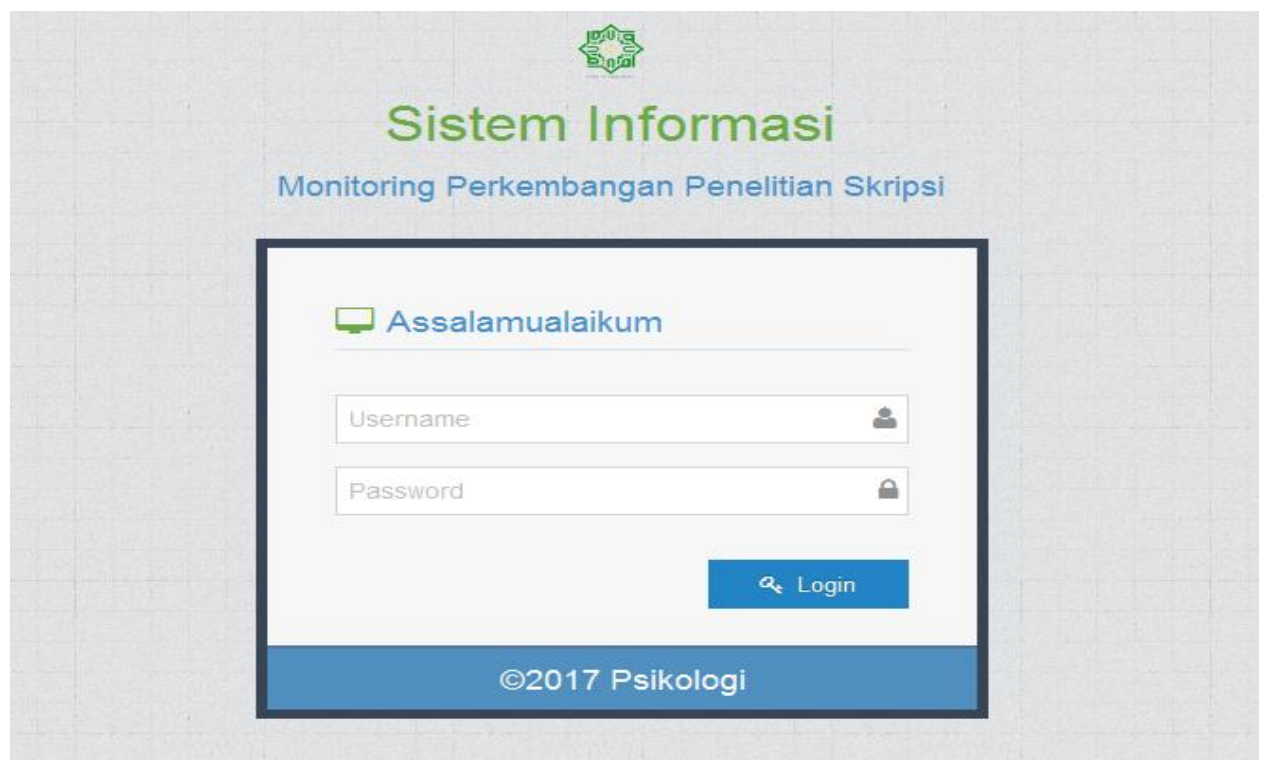

Gambar 3 Halaman Login

Pada tampilan halaman input ini terdapat menu-menu untuk mengisi dan merubah data dari setiap user. Tampilan dari halaman tersebut dapat dilihat pada Gambar 4. 
An Beranda

\$ Profil

Gil Dotalasiter

: DotaUser

Nama Lengkap Drs. A. Kharani Nur

Username admin

Password $\quad$ *Biarkan kosong jka password tak diubah

(2017 Psikologi

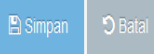

Gambar 4 Halaman Input Data Diri

Pada tampilan halaman dashboard admin ini terdapat halaman yang menampilkan info umum. Tampilan dari halaman tersebut dapat dilihat pada Gambar 5.

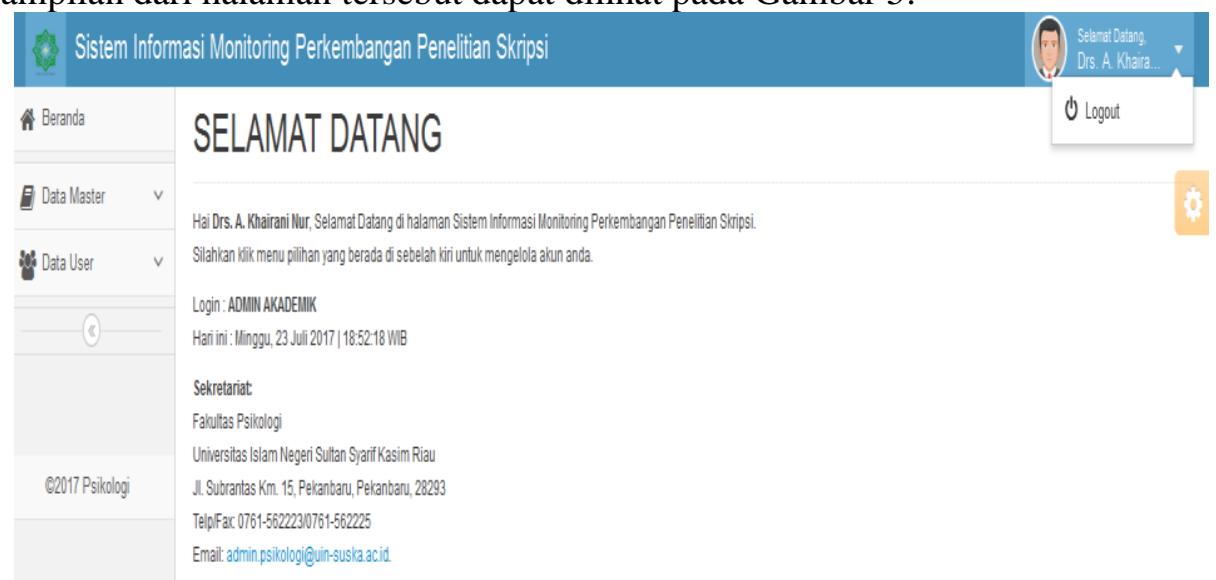

Gambar 5 Halaman Dashboard Admin

Pada tampilan halaman kelola data ketua bagian ini terdapat menu-menu untuk mengisi data setiap ketua bagian. Tampilan dari halaman tersebut dapat dilihat pada Gambar 6

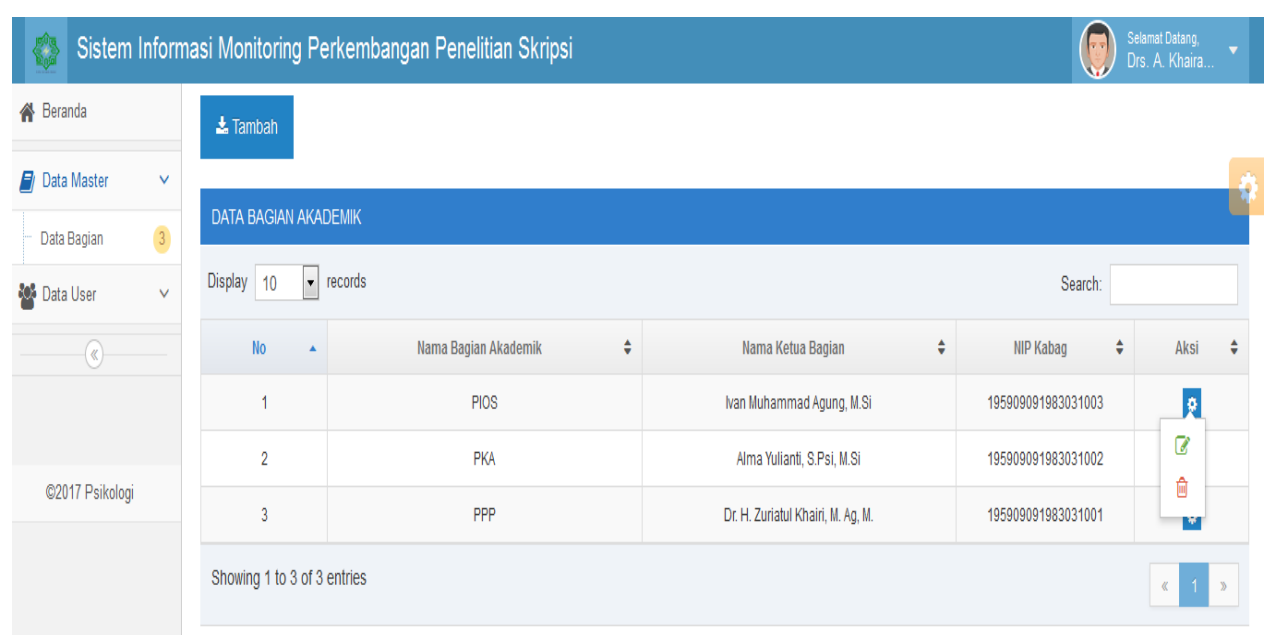

Gambar 6 Halaman Kelola Data Ketua Bagian 
Pada tampilan halaman kelola data dosen ini terdapat menu-menu untuk mengisi data setiap dosen. Tampilan dari halaman tersebut dapat dilihat pada Gambar 7.

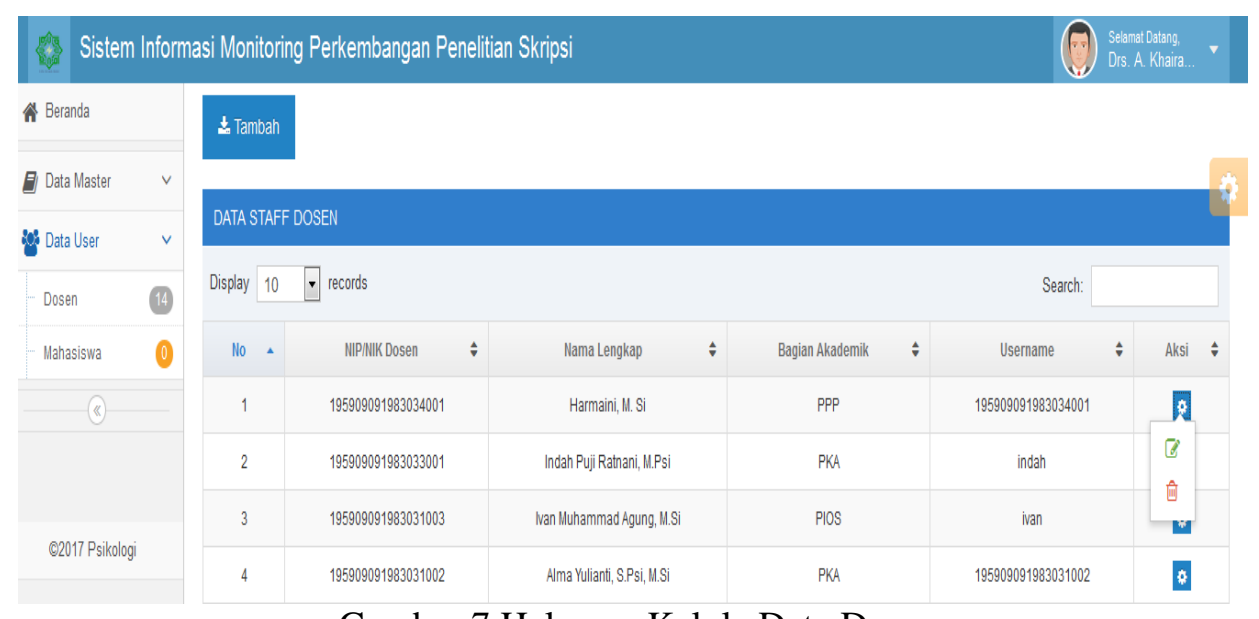

Gambar 7 Halaman Kelola Data Dosen

Pada tampilan halaman kelola data mahasiswa ini terdapat menu-menu untuk mengisi data setiap Mahasiswa. Tampilan dari halaman tersebut dapat dilihat pada Gambar 8.

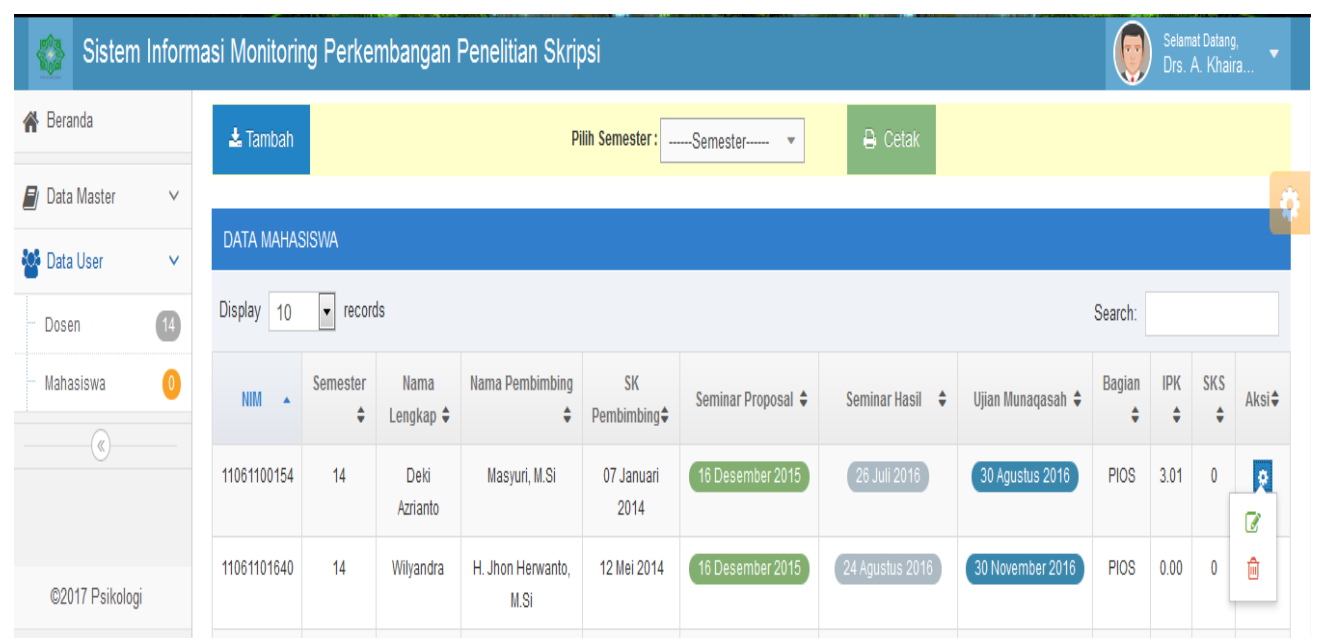

Gambar 8 Halaman Kelola Data Mahasiswa

Pada tampilan halaman dashboard ketua bagian ini terdapat halaman yang menampilkan info umum. Tampilan dari halaman tersebut dapat dilihat pada Gambar 9.

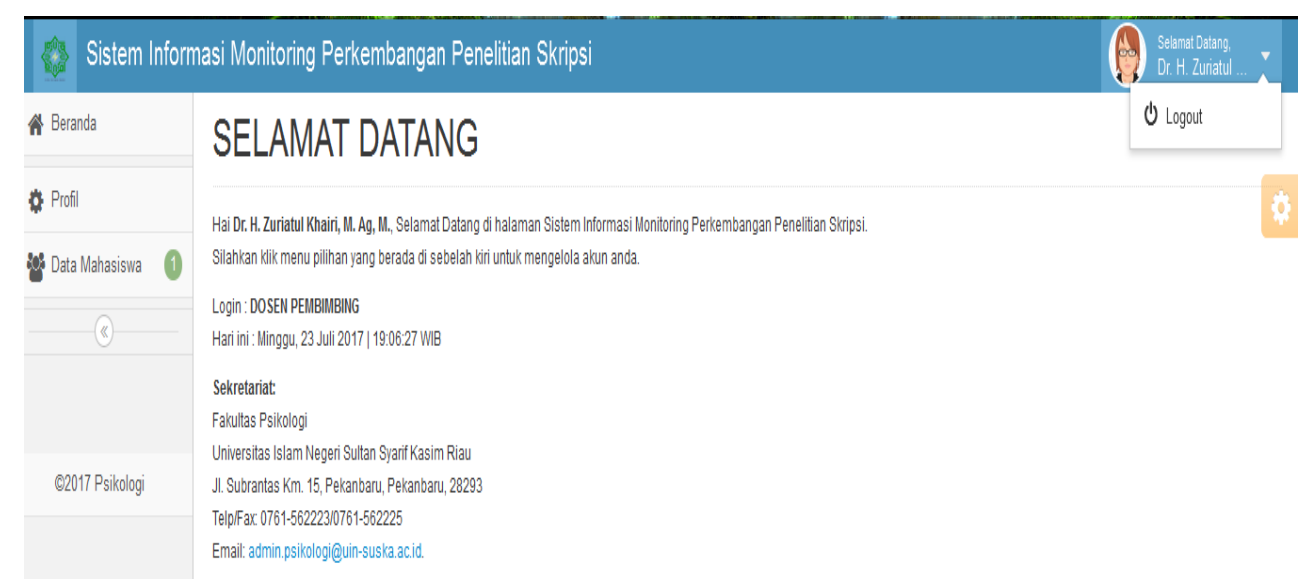

Gambar 9 Halaman Dashboard Ketua Bagian 
Pada tampilan halaman laporan mahasiswa keseluruhan ini terdapat halaman yang menampilkan laporan perkembangan skripsi semua mahasiswa. Tampilan dari halaman tersebut dapat dilihat pada Gambar 10.

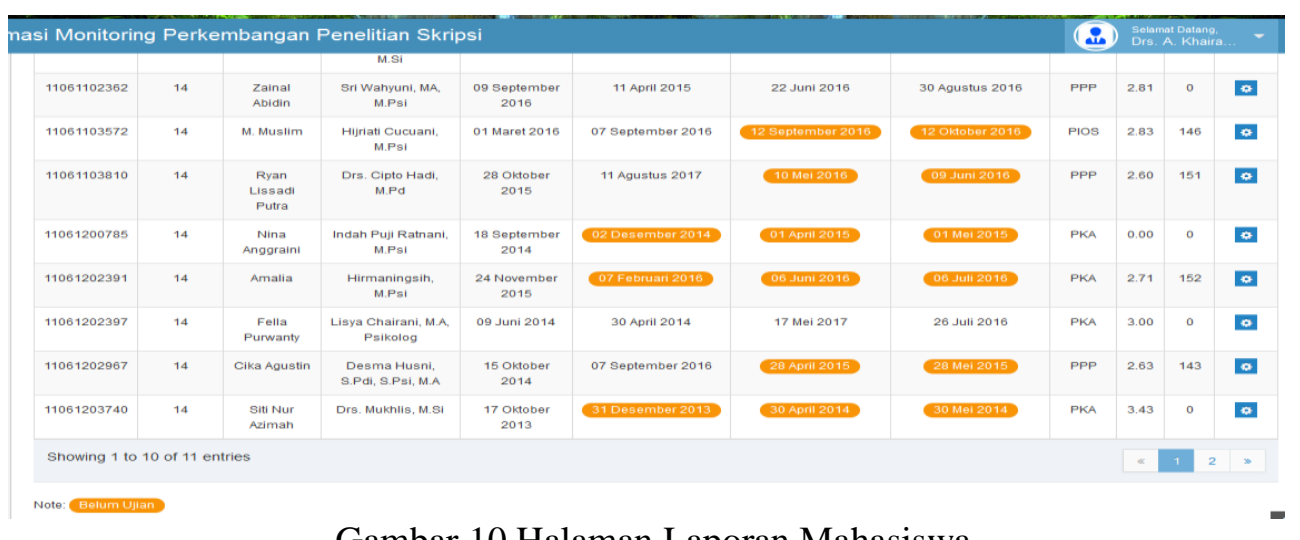

Gambar 10 Halaman Laporan Mahasiswa

Pada tampilan halaman laporan mahasiswa bimbingan ini terdapat halaman yang menampilkan laporan perkembangan skripsi mahasiswa perbimbingan dari masing-masing dosen pembimbing. Tampilan dari halaman tersebut dapat dilihat pada Gambar 11.

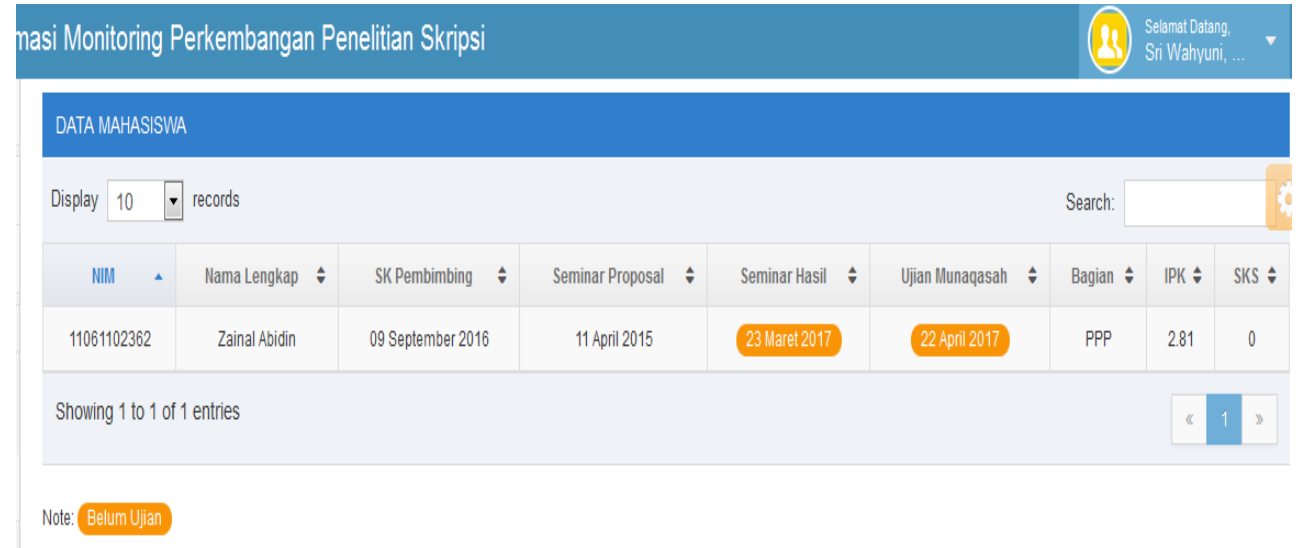

Gambar 11 Halaman Laporan Mahasiswa Bimbingan

Pada tampilan halaman dashboard dosen ini terdapat halaman yang menampilkan info umum. Tampilan dari halaman tersebut dapat dilihat pada Gambar 12.

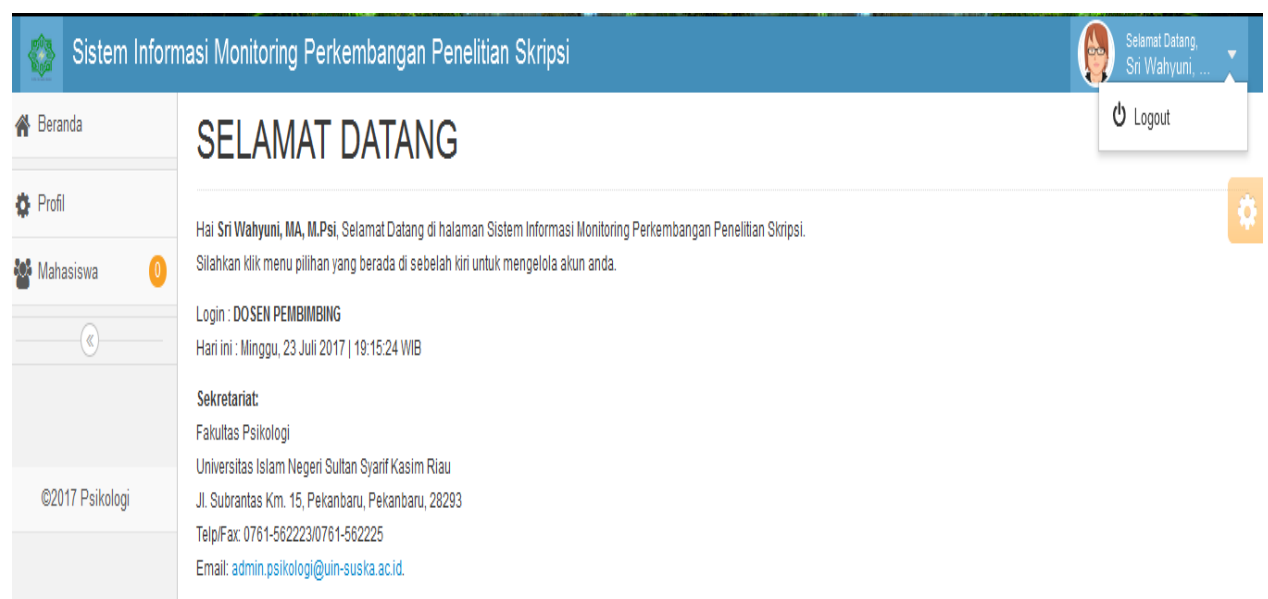

Gambar 12 Halaman Dashboard Dosen 
Pada tampilan halaman dashboard Mahasiswa ini terdapat halaman yang menampilkan info tentang perkembangan skripsi pada setiap mahasiswa. Tampilan dari halaman tersebut dapat dilihat pada Gambar 13.

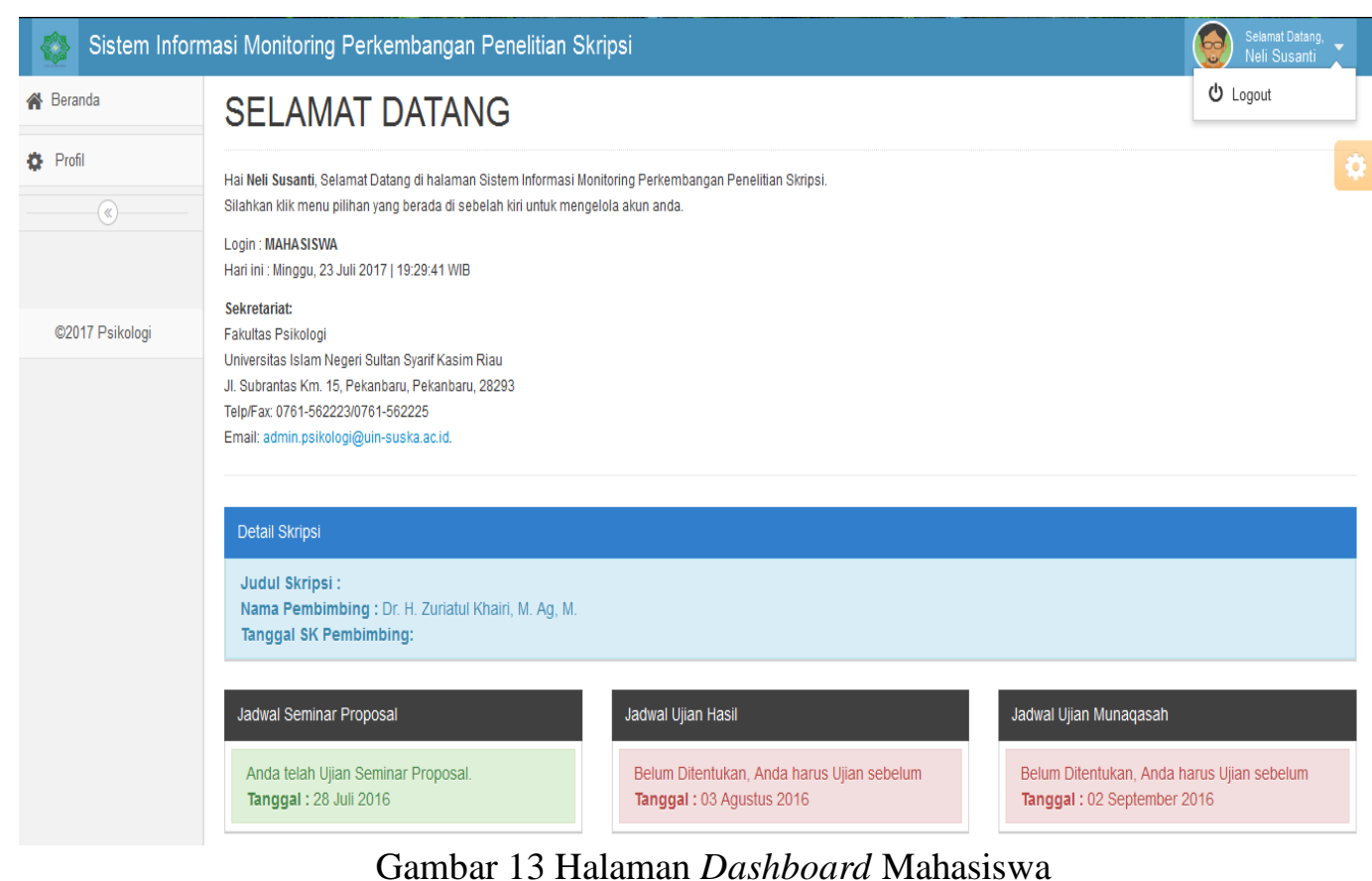

Pada tampilan reminder system ini terdapat menu-menu untuk pengiriman pesan melalui gmail sebagai peringatan kepada mahasiswa. Tampilan dari halaman tersebut dapat dilihat pada Gambar 14.

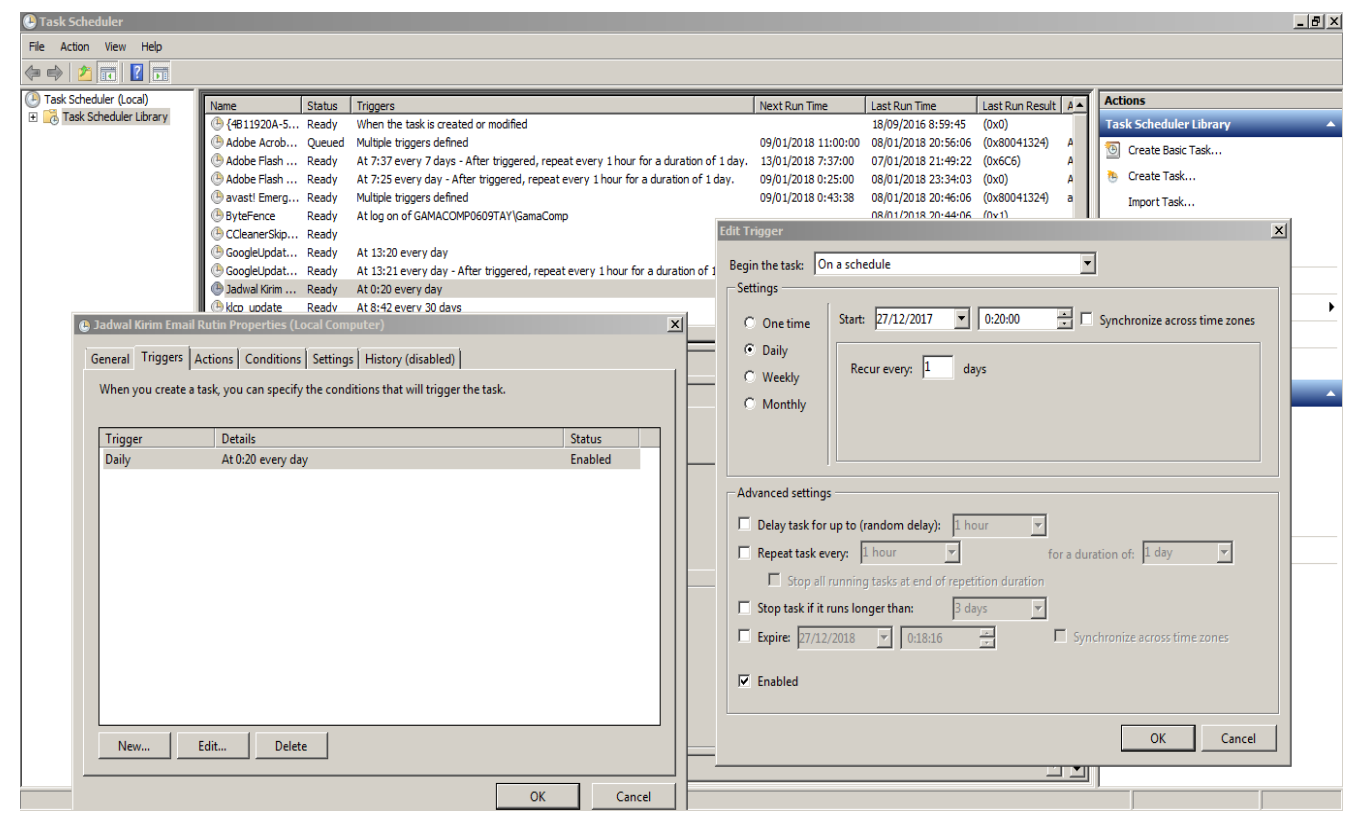

Gambar 14 Tampilan Pengatur Reminder System

Pada tampilan reminder system ini terdapat halaman info peringatan kemajuan skripsi setiap mahasiswa. Tampilan dari halaman tersebut dapat dilihat pada Gambar 15. 


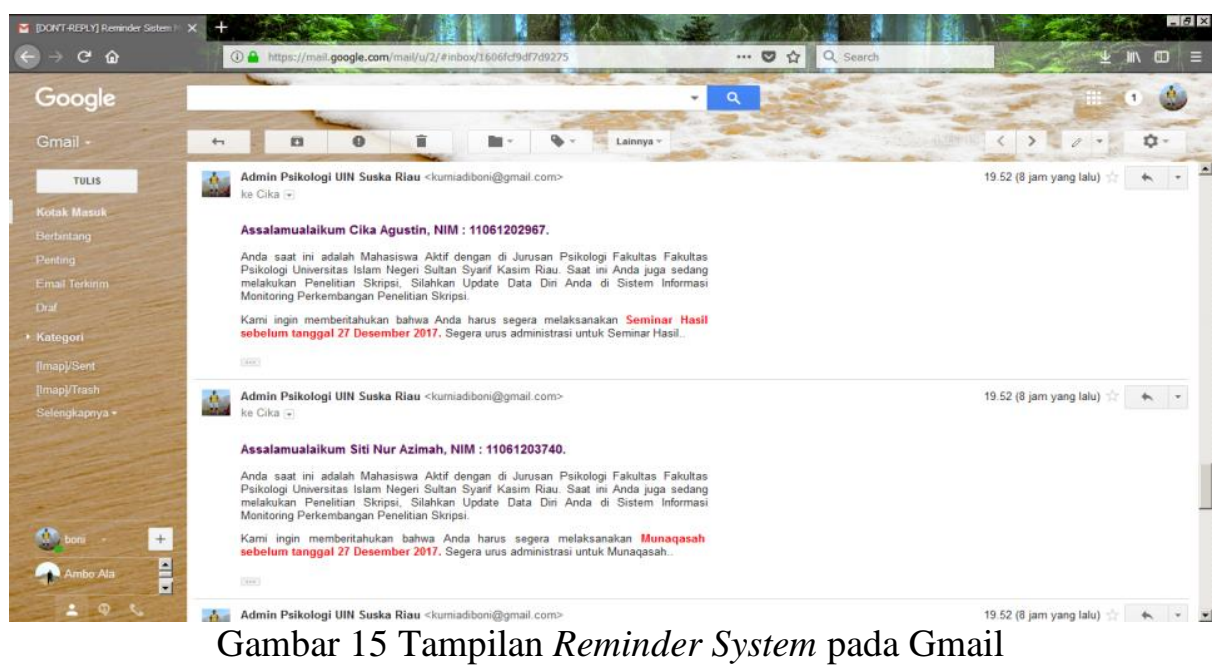

\section{Kesimpulan}

Sistem informasi perkembangan penelitian yang dibangun dapat melakukan pengumpulan data pada mahasiswa, dosen, kepala sub bagian serta informasi jadwal ujian dan menghasilkan pelaporan yang lebih baik yang akan diberikan kepada mahasiswa, dosen dan kepala sub bagian.Sistem informasi perkembangan penelitian yang dibangun yang tepat guna yaitu mampu mendidik mahasiswa yang mengharuskan menyelesaikan skripsi sesuai dengan rekomendasi tanggal yang ditentukan dan akan menghasilkan banyak mahasiswa yang selesai skripsinya dengan tepat waktu, serta berdaya guna yaitu sistem dapat memberikan informasi dan memberikan monitoring kepada mahasiswa, dosen dan kepala sub bagian secara langsung dengan menggunakan akun kepada masing-masing user.

\section{Daftar Pustaka}

[1] Hariyadi S, A Haris, F Anto, WA Sari. Identifikasi Faktor-Faktor Yang Mempengaruhi Penyelesaian Skripsi Pada Mahasiswa S1 Psikologi Di Kota Semarang. Jurnal Penelitian Pendidikan. 2017; Vol (34):155-60.

[2] Hartato U. Faktor-Faktor Yang Mempengaruhi Penyelesaian Skripsi Mahasiswa Pendidikan Akuntansi Universitas Negeri Yogyakarta. Jurnal Pendidikan Akuntansi. 2016; Vol (XIV) : 64-73

[3] Aprisa, S Monalisa. Rancang Bangun Sistem Informasi Monitoring Perkembangan Proyek Berbasis Web ( Studi Kasus : PT . Inti Pratama Semesta ). Jurnal Rekayasa dan Manajemen Sistem Informasi. 2015; Vol 1: 49-54.

[4] Roby V, H Anjik, S Arifin, P Widodo. Aplikasi Scheduler Dan Reminder Berbasis Web Untuk Kelompok Profesional ( Studi Kasus Di PT . Sarana Permata Container Semarang )Daftar Pustaka.Jurnal TELEMATIKA. 2010; Vol (06): 1-10

[5] Sevani GN. SMS Based Gateway Patient Medication Reminder Application Aplikasi Reminder Pengobatan Pasien Berbasis SMS Gateway. Jurnal INKOM. 2013; Vol (7) : $11-20$.

[6] Charibaldi N, DB Wijayanto. Aplikasi Scheduler Dan Reminder Berbasis Web Untuk Kelompok Profesional ( Studi Kasus Di PT . Sarana Permata Container Semarang ). Jurnal Telematika. 2010; Vol (06):1-10. [7] Ibrahim A. Pengembangan Sistem Informasi Monitoring Tugas Akhir Berbasis Short Message Service ( SMS ) Gateway di Fasilkom Unsri. Jurnal JUSI. 2011; Vol (1) : 81-92.

[8] Yani A, N Jafar. Pengaruh Sms Reminder Terhadap Perilaku Ibu Hamil Mengonsumsi Tablet Fe The Effect of SMS Reminder on Pregnant Mother Behaviour Consuming Iron Tablet.Jurnal MKMI. 2017; Vol (13) :12-20. 
[9] Yasin, Verdy. Rekayasa Perangkat Lunak Berorientasi Objek. Jakarta: Penerbit Mitra Wacana Media. 2012.

[10] Sugiarti, Yuni. Analisa Perancangan UML. Jakarta: Penerbit Graha Ilmu. 2012.

[11] Sulhan. Moh. Pengembangan Aplikasi Berbasis Web dengan PHP \& SHP. Malang: Penerbit Gava Media. 2006.

(c) (1) (2)

BY SA Digital Zone: Jurnal teknologi informasi dan Komunikasi is licensed under a Creative Commons Attribution International (CC BY-SA 4.0) 